\title{
ESTUDO COMPUTACIONAL DA INTERAÇÃO ENTRE O ELEMENTO DE TERRA RARA LANTÂNIO E OS EXTRATANTES DEHPA E P507
}

\author{
*Thayane P. Wandermurem ${ }^{1,2}$ (IC), Fernanda B. da Silva ${ }^{1}$ (PQ), Maurício T. M. Cruz ${ }^{2}$ \\ (PQ), Letícia M. Prates ${ }^{2}$ (PG), Júlio C. G Correia ${ }^{1}$ (PQ), Ysrael M. Vera ${ }^{1}$ (PQ). \\ thay.wandermurem@gmail.com \\ ${ }^{1}$ Centro de Tecnologia Mineral - CETEM/MCTI. Rio de Janeiro - RJ. Brasil \\ ${ }^{2}$ Universidade Estadual do Rio de Janeiro - UERJ. Rio de Janeiro - RJ. Brasil
}

Palavras-chave: Terras raras, extratante mineral, modelagem molecular

Elementos de terras raras (ETR) são um grupo de elementos químicos da série lantanídica que possuem um comportamento químico parecido[1]. Os ETR são altamente importantes na área de material avançado e sua aplicação vem crescendo a cada ano. Devido a isso, a separação e purificação desses elementos tem ganhado nas últimas décadas [2]. A separação normalmente é feita por meio da técnica de extração de solvente. O uso de um extratante seletivo e estável para um metal específico é essencial para reduzir custos do produção, aumentando a qualidade do produto e minimizando o impacto ambiental [3]. Compostos que possuem grupos que aumenta, a hidrofobicidade da molécula ligante, como o DEHPA (ácido di(2-etil-hexil) fosfórico) e o P507 (2-etil-hexil fosfônico éster mono-2-etilhexil) contribuem para a extração de terras-raras [4,5]. O objetivo do trabalho foi estudar a interação dos complexos LaDEHPA e La-P507, para validação de um método computacional e aplicá-lo na elaboração de novos extratantes mais eficientes, econômicos e seletivos. Todas as estruturas moleculares propostas para os complexos foram otimizadas pela Teoria do Funcional de Densidade (DFT) empregando o funcional híbrido B3LYP. Os elétrons foram descritos pelo conjunto base D95V, 6-31G(d) e LANL2DZ. Os processos de transferência eletrônica $\mathrm{La}-\mathrm{O}$ nos complexos foram obtidos por meio de cálculos dos Orbitais Naturais de Ligação (NBO). O pacote computacional Gaussian 03W e o Gauss View 3.0 foi utilizado para realização dos cálculos. Neste trabalho foram obtidas as estruturas de mínimo de energia para as bases conjugadas dos extratantes DEHPA e P507. Sobre tais estruturas otimizadas, pôde-se comparar a basicidade da base conjugada de ambos extratantes, tanto pela teoria de Pearson, quanto pela Teoria de Lewis, por meio das energias dos orbitais de fronteira HOMO e LUMO. Para a avaliação do efeito eletrônico promovido na ligação $\mathrm{La}-\mathrm{O}$, utilizou-se uma estrutura representativa com uma metila (R1, Figuras 1a e 1b). Para análise do efeito estérico, adicionou-se uma segunda metila às estruturas (R2, Figuras $2 \mathrm{c}$ e $2 \mathrm{~d})$. A energia de ligação média do cátion $\mathrm{La}^{3+}$ nos ligantes R1 para DEHPA e P507 foi calculada com a finalidade de verificar a intensidade da interação La-extratante. Os resultados apontam que a interação de $\mathrm{La}^{3+}$ com DEHPA envolve uma energia superior ao de P507 (Figuras 1a e 1b). Com o aumento da cadeia carbônica (R2), a interação La-extratante aumenta de intensidade para ambos os ligantes, porém se mantém superior para DEHPA (Figuras 1c e 1d). 


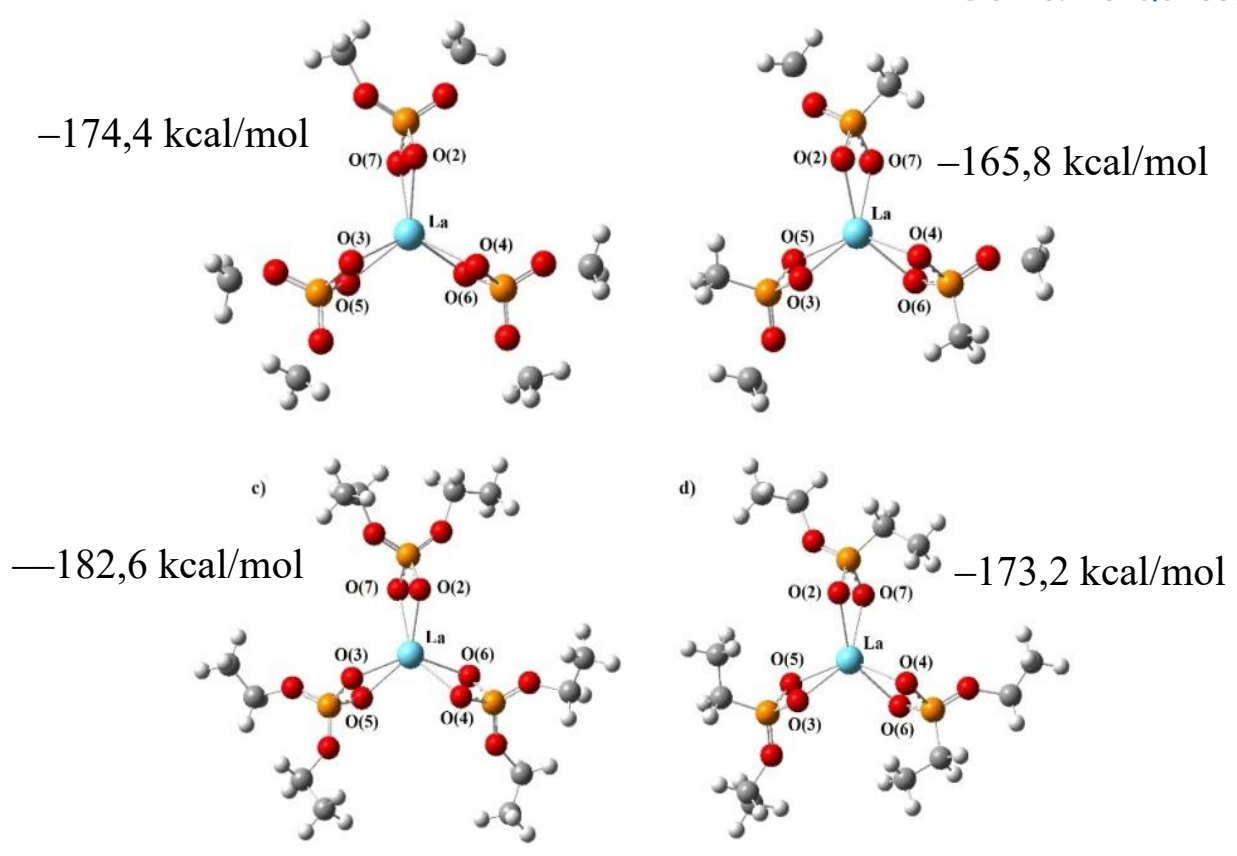

Figura 1. a) Complexo La-DEHPA com R1 e b) Complexo La-P507 com R1, c) Complexo La-DEHPA com R2 e d) Complexo La-P507 com R2.

O cálculo dos Orbitais Naturais de Ligação (NBO) mostra que a transferência eletrônica $\mathrm{O} \rightarrow$ La com o extratante DEHPA é ligeiramente superior ao P507. Sendo assim, que os resultados obtidos pelo presente trabalho corroboram com os resultados encontrados na literatura que mostram uma maior eficiência em extração do DEHPA em relação ao P507. A validação de um método computacional fornecerá dados para a obtenção de novas estruturas capazes de extrair seletivamente os elementos de terras raras.

Agradecimentos: Os autores agradecem ao CNPq, UERJ and LABMOL/CETEM.

\section{Bibiografia}

[1] Falandysz, J.; Sapkota, A.; Medyk, M.; Feng, X. Rare Earth In Parasol Mushroom Macrolepiota Procera. Food Chemistry, (2016).

[2] Abreu, R. D.; Morais, C.A. Estudo Fracionamento De Elementos Terras Raras Pesados Por Extração Por Solventes Com Ênfase na Separação de Térbio. ENTMME, (2011).

[3] Hoang, A. S.; Tran, T. H.; Nguyen, H. N.; Vu, H. S.; Vo, T. P.; Phan, C.; Nguyen, T. V. Synthesis of oxime from a renewable resource for metal extraction. Korean J. Chem. Eng., 32(8), 1598-1605, (2015).

[4] Nascimento, M.; Vera, Y.M.; Valverde, B. M.; Gomes, R. C. Estudo De Separação De Terras Raras Usando Sistemas Extrantes Organofosforados. COBEQ (2014).

[5] Morais, C. A.; Ciminelli, V. S. T. Process Development For The Recovery Of HighGrade Lanthanum By Solvent Extraction. Hydrometallurgy, V.73, P.237-244, (2004). 